\title{
Plasmacytoma of the
} Nasolacrimal Duct Simulating Dacryocystitis: An Uncommon Presentation for

\section{Extramedullary Relapse of Multiple Myeloma}

\author{
Sevgi Kalayoglu-Besisik ${ }^{\mathrm{a}} \quad$ Ipek Yonal $^{\mathrm{a}}$ Fehmi Hindilerden $^{\mathrm{c}}$ \\ Mehmet Agan ${ }^{b}$ Deniz Sargin ${ }^{a}$ \\ Departments of ${ }^{\mathrm{a}}$ Internal Medicine and ${ }^{\mathrm{b}}$ Pathology, Istanbul Medical Faculty, \\ Istanbul University, and ${ }^{\mathrm{C} D i v i s i o n}$ of Hematology, Department of Internal \\ Medicine, Istanbul Bilim University, Istanbul, Turkey
}

\section{Key Words}

Dacryocystitis $\cdot$ Multiple myeloma $\cdot$ Nasolacrimal duct $\cdot$ Plasmacytoma

\begin{abstract}
The most common site for localized forms of plasma cell neoplasms (extramedullary plasmacytoma; EMP) is the upper respiratory tract, including the oropharynx, nasal cavities, sinuses and larynx. A 50-year-old woman with a history of myeloma in complete remission after autologous stem cell transplantation complained of two weeks of epiphora of the left eye with subsequent diplopia, bloody nasal discharge and progressive swelling around the nasolacrimal sac. A solitary mass in the left sinonasal area, extending to the nasolacrimal duct (NLD) was detected on MRI, whose histopathological examination was consistent with plasmacytoma. Further clinical investigation ruled out multiple myeloma (MM). The patient underwent debulking surgery and adjuvant chemotherapy followed by local radiotherapy in an attempt to achieve complete response. Despite being a rare entity, EMP of the NLD should be considered in the differential diagnosis of epiphora and dacryocystitis. To our knowledge, this is the first case of a plasmacytoma of the NLD presenting as isolated extramedullary relapse of MM. The follow-up in EMPs should include appropriate imaging studies, a systemic workup to rule out MM.
\end{abstract}




\section{Introduction}

Congenital or acquired nasolacrimal duct (NLD) obstruction is the most common abnormality of the lacrimal drainage system. NLD obstruction may be primary or secondary to infection, inflammation, neoplasm, trauma or mechanical causes. The mechanical obstruction of NLD by a plasmacytoma is rare. Herein, we report a 50 -yearold female patient who had presented with epiphora of the left eye and been treated initially as dacryocystitis. Distention of the lacrimal sac secondary to NLD obstruction was detected by imaging MRI. Histopathologic examination revealed plasma cell infiltration.

\section{Case Presentation}

A 50-year-old woman with a history of multiple myeloma (MM) in complete remission after highdose chemotherapy with autologous stem cell rescue was admitted with swelling and overtearing of the left eye. With the prediagnosis of NLD obstruction, dacryoscintigraphy was planned. In two weeks, erythema and swelling around the left eye and nose became evident. Antimicrobial therapy for one week was given with suspicion of dacryocystitis. Yet, the symptoms progressed with additional symptoms of diplopia and bloody discharge from left nose (fig. 1). MRI of the orbit and paranasal sinuses revealed a $3 \times 5 \times 7.5 \mathrm{~cm}$ mass in the left sinonasal area infiltrating the left anterior, medial, posterior ethmoidal sinuses, left nasal cavity, left maxillary sinus, left orbit, left soft and hard palates and displacing the left globe laterally. The mass also extended to the NLD, the left pterygomaxillary fossa, infratemporal fossa and middle cranial fossa (fig. 2). Excisional biopsy of the paranasal sinus revealed diffuse CD38-positive plasma cell infiltration with kappa light chain restriction ( $\mathrm{fig}$. 3 ). On serum protein electrophoresis, a monoclonal protein of $0.01 \mathrm{~g} / \mathrm{dl}$ was present and immunofixation electrophoresis in serum and urine showed the same amount of paraproteinemia as at the time of initial diagnosis as MM. Serum kappa light chain levels were increased (882 mg/l). Serum albumin and beta 2-microglobulin levels were normal; serum LDH level was slightly increased. The final diagnosis was extramedullary relapse of MM. High-dose steroid was given as urgent treatment followed by debulking surgery including left maxillectomy, resection of the inferior orbital wall and a portion of the soft and hard palates. Histopathologic examination of the surgical material showed diffuse plasma cell infiltration (fig. 4). On postoperative orbital MRI, a $2.5 \times 2 \mathrm{~cm}$ residual mass in the left medial pterygoid muscle was present. One month after the surgery, allergic reaction developed against the prosthetic support material placed under the orbit resulting in orbital displacement. Hence, the remission induction chemotherapy was postponed. The prosthesis was removed. Biopsy sample from the orbital soft tissue showed granulation tissue, fibrosis and foreign body reaction. Radiotherapy was also postponed in anticipation for delay in wound healing. Two months later, orbital reconstruction was made by forehead flap. At that time, serum kappa light chain decreased to $109 \mathrm{mg} / \mathrm{l}$. Salvage chemotherapy with bortezomib, cyclophosphamide and dexamethasone for three courses was given. Three months later, radiotherapy at 36 Gy in 18 fractions was performed to the postoperative residual tissue at the left mastoid region.

\section{Discussion}

Plasma cell neoplasms are a group of entities characterized by the neoplastic proliferation of a single clone of plasma cells, typically producing a monoclonal immunoglobulin. Plasma cell tumors can manifest as a single lesion (solitary plasmacytoma) or as multiple lesions (MM). Solitary plasmacytomas most frequently originate from bone (plasmacytoma of bone) or arise in soft tissues as mass lesions (extramedullary plasmacytoma; EMP) [1,2]. EMPs, which account for approximately 3 percent of plasma cell malignancies, are most often located in the upper respiratory tract, including the oropharynx, nasal cavities, sinuses and larynx while the bone 
plasmacytoma frequently presents in the axial skeleton [3-5]. EMPs often present with signs or symptoms related to mass effect. Approximately 80 percent involve the upper respiratory tract (i.e., oronasopharynx and paranasal sinuses) causing epistaxis, nasal discharge (rhinorrhea), or nasal obstruction [6-9]. Orbital tumors are uncommon and often present with nonspecific findings mimicking the symptoms of dacryocystitis. EMP of the orbit is an even rarer entity with only a few cases reported to date [10]. Imaging features of EMPs are nonspecific. Histopathological examination differentiates these tumors from more common malignant entities such as natural killer cell lymphoma, squamous cell carcinoma, adenocystic carcinoma, rhabdomyosarcoma or metastasis from other primaries [11]. Systemic involvement must be ruled out by clinical, biochemical, hematological and radiological modalities both at the time of initial diagnosis and during follow-up.

The primary method of treatment of EMP is radiation therapy. The treatment of choice is external beam radiation at doses ranging from 4,000 to 6,000 cGy administered over 5 to 7 weeks. The role of surgery is generally limited to open biopsy for diagnosis or for debulking a large tumor. Complete excision of EMP is often difficult due to the close proximity to vital structures and large tumor size. Surgery can often cause significant functional and cosmetic deformity. The rate of local control for EMPs following treatment with radiotherapy or surgery is $75 \%$ to $95 \%$ [12]. In our case, adjuvant chemotherapy was administered in addition to local therapy to achieve complete response for extramedullary relapse of myeloma. Following completion of therapy, patients should be monitored for treatment complications and for possible relapse every 3 months for the first two years, every 6 months for an additional three years and every 1 or 2 years. A detailed history and physical examination as well as laboratory parameters including a complete blood count, serum creatinine, and calcium, serum and urine protein electrophoresis with immunofixation are required at each visit. If the extent of an EMP had been measured by an imaging modality prior to therapy, the same modality (e.g., MRI) should be repeated three to four months after completing therapy, and periodically thereafter.

\section{Acknowledgements}

We would like to thank the Otorhinolarnygology and Radiation Oncology Departments of Istanbul University, Istanbul Medical Faculty for their contributions to the diagnosis and treatment of our patient. We have obtained written permission from the patient to include her picture in this report.

\section{Disclosure Statement}

The authors have no conflicts of interest to disclose. 


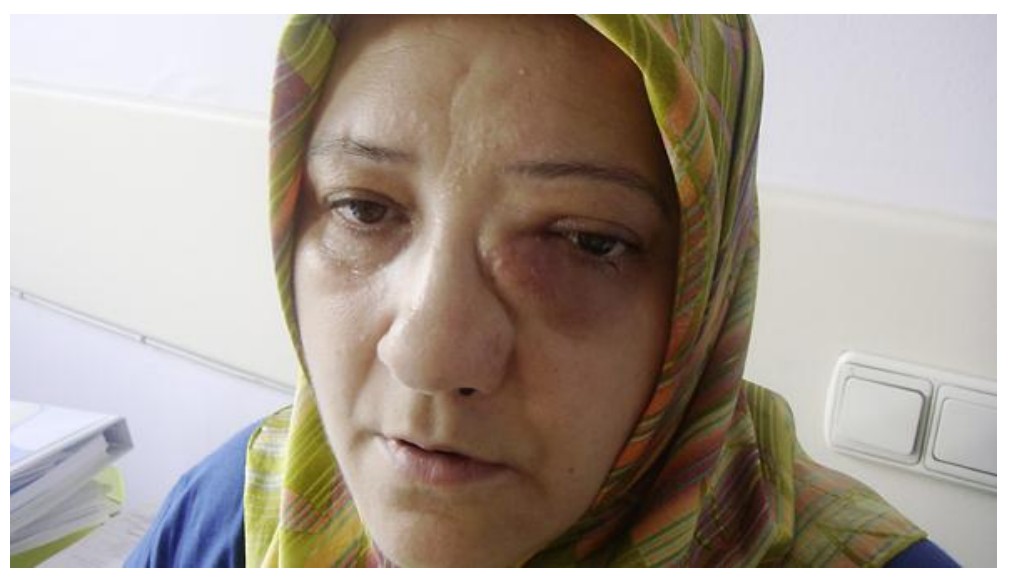

Fig. 1. Left eye swelling extending to the left side of the nose accompanied by bloody nasal discharge.

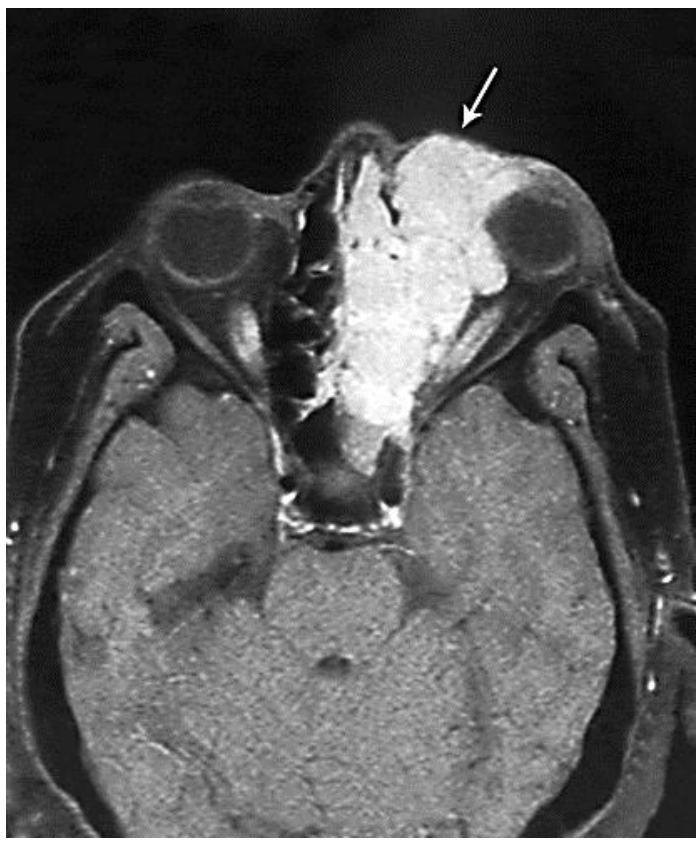

Fig. 2. MRI revealed a $3 \times 5 \times 7.5 \mathrm{~cm}$ mass in the left sinonasal area extending to the nasolacrimal duct (marked with arrow). 

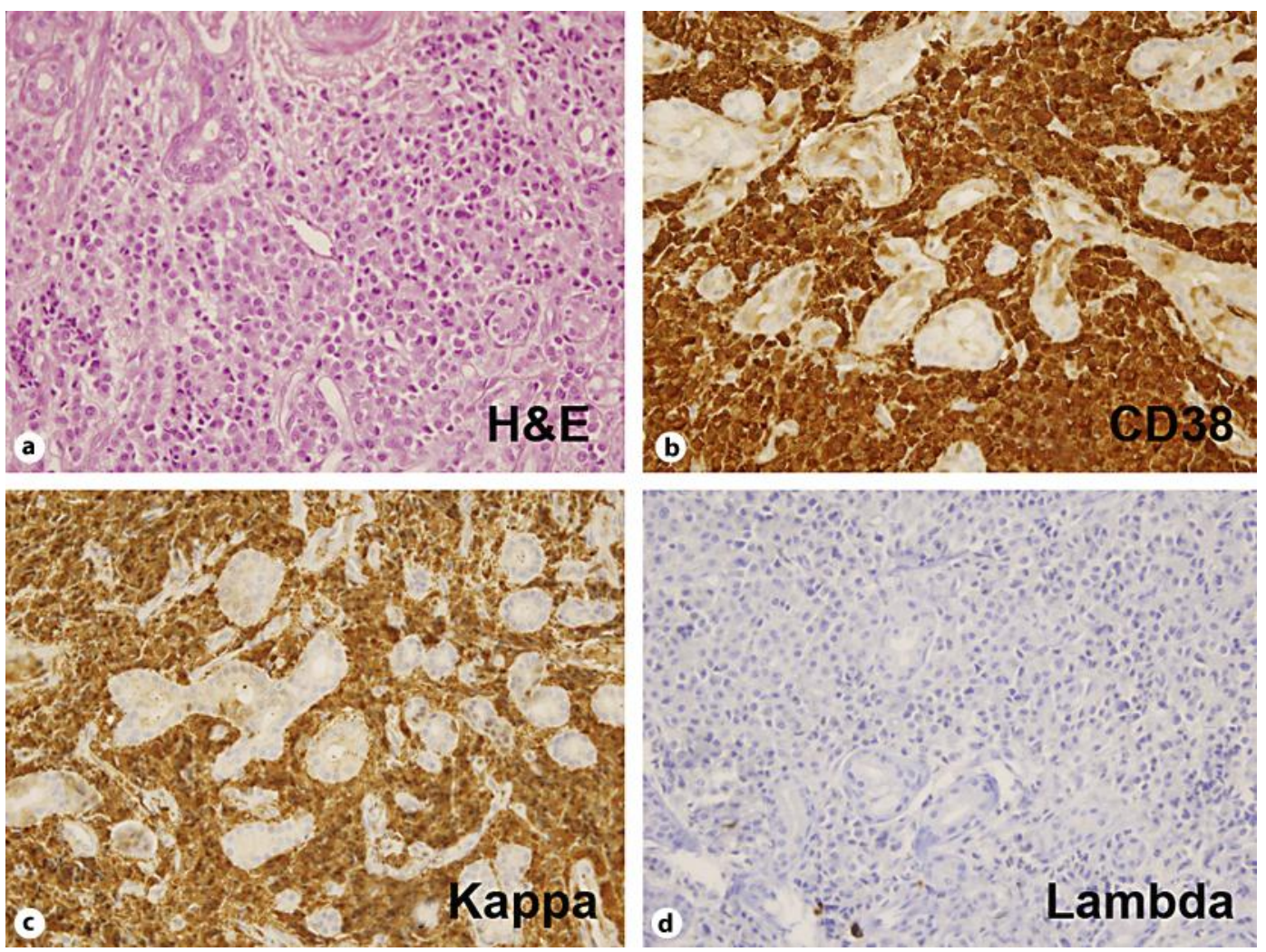

Fig. 3. Plasma cell infiltration within the mucosal glands (a, H\&E, $\times 400)$, the infiltrating cells positive for CD38 $(b, \times 400)$ and kappa light chain $(c, \times 400)$, and negative for lambda light chain $(d, \times 400)$.

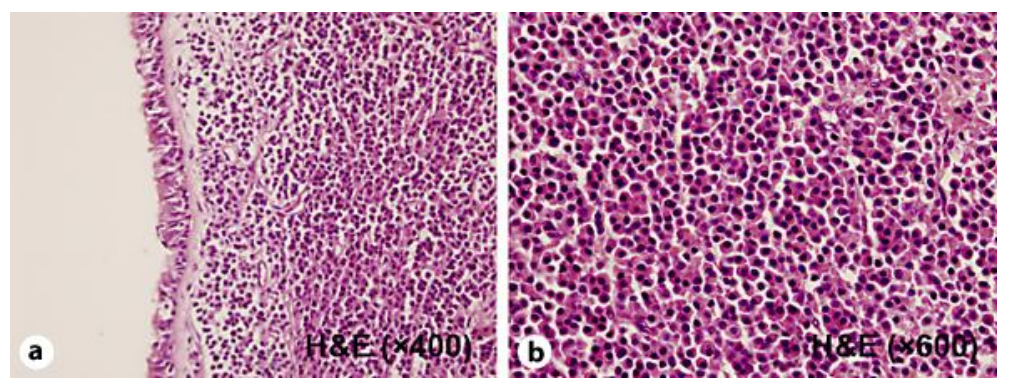

Fig. 4. Plasma cell infiltration underneath the surface epithelium in maxillary sinus $(a, H \& E, \times 400$; b, $H \& E, \times 600$ ). 


\section{References}

1 Jaffe ES, Harris NL, Stein H, Vardiman JW (eds): World Health Organization Classification of Tumours. Pathology and Genetics of Tumours of Haematopoietic and Lymphoid Tissues. IARC Press, Lyon, 2001.

-2 Soutar R, Lucraft H, Jackson G, et al: Guidelines on the diagnosis and management of solitary plasmacytoma of bone and solitary extramedullary plasmacytoma. Br J Haematol 2004;124:717-726.

3 Dimopoulos MA, Moulopoulos LA, Maniatis A, Alexanian R: Solitary plasmacytoma of bone and asymptomatic multiple myeloma. Blood 2000;96:2037-2044.

-4 Dores GM, Landgren 0, McGlynn KA, et al: Plasmacytoma of bone, extramedullary plasmacytoma, and multiple myeloma: incidence and survival in the United States, 1992-2004. Br J Haematol 2009;144:8694.

5 Shih LY, Dunn P, Leung WM, et al: Localised plasmacytomas in Taiwan: comparison between extramedullary plasmacytoma and solitary plasmacytoma of bone. Br J Cancer 1995;71:128-133.

6 Pavithran K, Doval DC, Rao CR, et al: Pediatric solitary plasmacytoma. Acta Oncol 1997;36:83-84.

7 Boos N, Goytan M, Fraser R, Aebi M: Solitary plasma-cell myeloma of the spine in an adolescent. Case report of an unusual presentation. J Bone Joint Surg Br 1997;79:812-814.

8 Bataille R, Sany J: Solitary myeloma: clinical and prognostic features of a review of 114 cases. Cancer 1981;48:845-851.

-9 International Myeloma Working Group: Criteria for the classification of monoclonal gammopathies, multiple myeloma and related disorders: a report of the International Myeloma Working Group. Br J Haematol 2003;121:749-757.

10 Sia DI, Cannon PS, Selva D: Extramedullary plasmacytoma arising from the lacrimal gland. Clin Experiment Ophthalmol 2010;38:895-898.

11 Ooi GC, Chim JC, Au WY, Khong PL: Radiologic manifestations of primary solitary extramedullary and multiple solitary plasmacytomas. AJR Am J Roentgenol 2006;186:821-827.

12 Michalaki VJ, Hall J, Henk JM, Nutting CM, Harrington KJ: Definitive radiotherapy for extramedullary plasmacytomas of the head and neck. Br J Radiol 2003;76:738-741. 